\title{
Preparation, differential thermal analysis and crystal structure of the new quaternary compound $\mathrm{CuVInSe}$
}

\author{
Gustavo Marroquín $^{a}$, Gerzon E. Delgado ${ }^{b, *}$, Pedro Grima-Gallardo ${ }^{c, d}$, and Miguel Quintero ${ }^{c}$ \\ ${ }^{a}$ Escuela Superior de Ingeniería Química e Industrias Extractivas, \\ Instituto Politécnico Nacional, Zacatenco 07738, Ciudad de México, México. \\ ${ }^{b}$ Laboratorio de Cristalografía, Departamento de Química, \\ Facultad de Ciencias, Universidad de Los Andes, Mérida 5101, Venezuela. \\ *e-mail: gerzon@ula.ve \\ ${ }^{c}$ Centro de Estudios de Semiconductores, Departamento de Física, \\ Facultad de Ciencias, Universidad de Los Andes, Mérida 5101, Venezuela. \\ ${ }^{d}$ Centro Nacional de Tecnologías Ópticas (CNTO) y \\ Centro Investigaciones de Astronomía (CIDA), Mérida 5101, Venezuela.
}

Received 24 May 2018; accepted 3 July 2018

\begin{abstract}
The crystal structure of the quaternary compound $\mathrm{CuVInSe}_{3}$, belonging to the system $\left(\mathrm{CuInSe}_{2}\right)_{1-x}(\mathrm{VSe})_{x}$ with $x=1 / 2$, was analyzed using X-ray powder diffraction data. This material was synthesized by the melt and anneal method and crystallizes in the tetragonal space group $\mathrm{P} \overline{4} 2 \mathrm{c}\left(\mathrm{N}^{\circ} 112\right)$, with unit cell parameters $a=5.7909(4) \AA, c=11.625(1) \AA, V=389.84(5) \AA^{3}$. The Rietveld refinement of 25 instrumental and structural variables led to $R_{\exp }=6.6 \%, R_{p}=8.7 \%, R_{w p}=8.8 \%$ and $S=1.3$ for 4501 step intensities, and 153 independent reflections. This compound has a normal adamantane structure and is isostructural with CuFeInSe $\mathrm{F}_{3}$. The DTA indicates that this compound melts at $1332 \mathrm{~K}$.
\end{abstract}

Keywords: Chemical synthesis; X-ray powder diffraction; crystal structure; differential thermal analysis; chalcogenide; semiconductor.

PACS: 61.05.cp; 61.50.Nw; 61.66.Fn; 61.40.b

\section{Introduction}

The addition of a II-VI binary to chalcopyrite I-III-VI 2 structures, produces alloys with composition (I-III- $\left.-\mathrm{VI}_{2}\right)_{1-x}$ (II$\mathrm{VI})_{x}$. All the possible phases fulfill the rules for the formation of adamantane compounds, giving materials with semiconductor behaviour, which belong to the compound families derivatives of the II-VI binary [1]. Recently, it has been observed that when $x=1 / 2$, the formation of alloys with composition I-II-III- $\mathrm{VI}_{3}$ is obtained [2-7]. In a lately work carried out on the $\mathrm{CuFeInSe} \mathrm{I}_{3}$ material it was found that this compound crystallizes in a primitive tetragonal structure with space group $\mathrm{P} \overline{4} 2 \mathrm{c}$ [8] known as P-chalcopyrite [9]. This result is in contrast with the space group I $\overline{4} 2 \mathrm{~d}$ of the related I-III- $-\mathrm{VI}_{2}$ chalcopyrite structure, indicating a degradation of symmetry but maintaining the volume almost unchanged.

These types of materials have received considerable attention mainly because they can be useful for their potential applications in the fabrication of low cost solar cells and their large magneto-optical effects, which are observed when II are paramagnetic atoms [10,11]. We are currently investigating the synthesis and structural characterization of chalcogenide diamond-like families [12-16], and as part of ongoing studies, in this work we report the synthesis and a crystallographic characterization of the new chalcogenide quaternary compound $\mathrm{CuVInSe}{ }_{3}$, which belong to the system $\left(\mathrm{Cu}-\mathrm{In}-\mathrm{Se}_{2}\right)_{1-x}(\mathrm{VSe})_{x}$ where $x=1 / 2$. The structural study was carried out by Rietveld refinement using X-ray powder diffraction data.

\section{Experimental}

\subsection{Preparation of the sample}

Polycrystalline sample was synthesized using the melt and annealing technique. Stoichiometric quantities of the elements with purity of $99.99 \%$ were charged in a synthetic silica glass ampoule, which was previously subjected to pyrolysis in order to avoid reaction of the starting materials with silica glass. Then, the ampoule was sealed under vacuum ( $\sim 10^{-4}$ Torr) and the fusion process was carried out inside a furnace (vertical position), heated up to $1500 \mathrm{~K}$ at a rate of $20^{\circ} / \mathrm{h}$, with a stop of $48 \mathrm{~h}$ at $490 \mathrm{~K}$ (melting point of Se). The ampoule was shaken using a mechanical system during all the heating process in order to guarantee the complete mixing of all the elements and the formation of binary species at low temperature. Then, the temperature was gradually decreased until $600 \mathrm{~K}$ and this temperature was kept for 60 days. Finally, the sample was cooled to room temperature by switching off the furnace.

\subsection{Scanning electron microscopy}

The stoichiometric relation of the samples was investigated by Scanning Electron Microscopy (SEM) technique, using a FE-8 SEM, Jeol 6301-F equipment. The micro-chemical composition was found using an energy dispersive $\mathrm{X}$-ray spectrometer (EDS) coupled with a computer-based multichannel analyzer (MCA), (Delta III analysis and Quantex software, Kevex). For the EDS analysis K $\alpha$ lines were used. Accelerating voltage was $15 \mathrm{kV}$. The samples were tilted by $35^{\circ}$. A standardless EDS analysis was 
TABLE I. Experimental parameters for data collection of the $\mathrm{CuVInSe}_{3}$ compound.

\begin{tabular}{cccc}
\hline diffractometer & Siemens D5005 & $2 \theta$ range & $10-100^{\circ}$ \\
radiation & $\mathrm{CuK} \alpha$ & step size & $0.02^{\circ}(2 \theta)$ \\
instrumental settings & $40 \mathrm{kV}, 30 \mathrm{~mA}$ & counting time & $40 \mathrm{~s}$ \\
wavelenght & $\lambda=1.54056 \AA$ & specimen rotation & 15 r.p.m. \\
monocrhomator & graphite & external standard & quartz \\
scan mode & $\theta / 2 \theta$ (reflection) & temperature & $298(1) \mathrm{K}$ \\
\hline
\end{tabular}

made with a relative error of $\pm 5 \%$ and detection limits of the order of $0.3 \mathrm{wt} \%$, where the k-ratios were based on theoretical standards.

\subsection{Differential thermal analysis}

The differential thermal analysis (DTA) was carried out in a fully automatic Perkin-Elmer apparatus with Pt/Pt-Rh thermocouples. Au or Ag was used as internal standards, according to the expected melting point of the sample. The heating and cooling rates were controlled to $20 \mathrm{~K} / \mathrm{h}$. Transition temperatures were manually obtained from the $\Delta \mathrm{T}$ vs. $\mathrm{T}$ graph with the criteria that the transition occurs at the intersection of the base line with the slope of the thermal transition peak, as usually [3].

\subsection{X-ray powder diffraction}

A small amount of the sample was ground in an agate mortar and pestle and mounted on a flat zero-background holder covered with a thin layer of petroleum jelly. A Siemens D5005 powder diffractometer was used for data collection with the conditions given in Table I. The X-ray Power Difraction (XRPD) data was collected at 293(1) $\mathrm{K}$, in $\theta / 2 \theta$ reflection mode using a Siemens D5005 diffractometer equipped with an X-ray tube. The specimen was scanned from $10^{\circ}-100^{\circ}$ $2 \theta$, with a step size of $0.02^{\circ}$ and counting time of $40 \mathrm{~s}$. Quartz was used as an external standard.

\section{Results and Discussion}

\subsection{Scanning Electron Microscopy}

The obtained ingot (15 mms long and $8 \mathrm{mms}$ diameter) was homogeneous at sight, with no voids in the surface and light gray color. As it is routine in our laboratory, stoichiometry and homogeneity of the ingots are tested using scanning electron microscopy (SEM); for that, a slice $1 \mathrm{~mm}$ thick was cut from the center of the ingot. In Fig. 1, the results of SEM measurements are shown. It When measured, a little excess of selenium was found in the points located in the inner part of the slice whereas for the nearest points to the external surface of the ingot the selenium is in defect. This behavior may be due to the long period of annealing (30 days) for which little amounts of selenium in the surface of the ingot may go

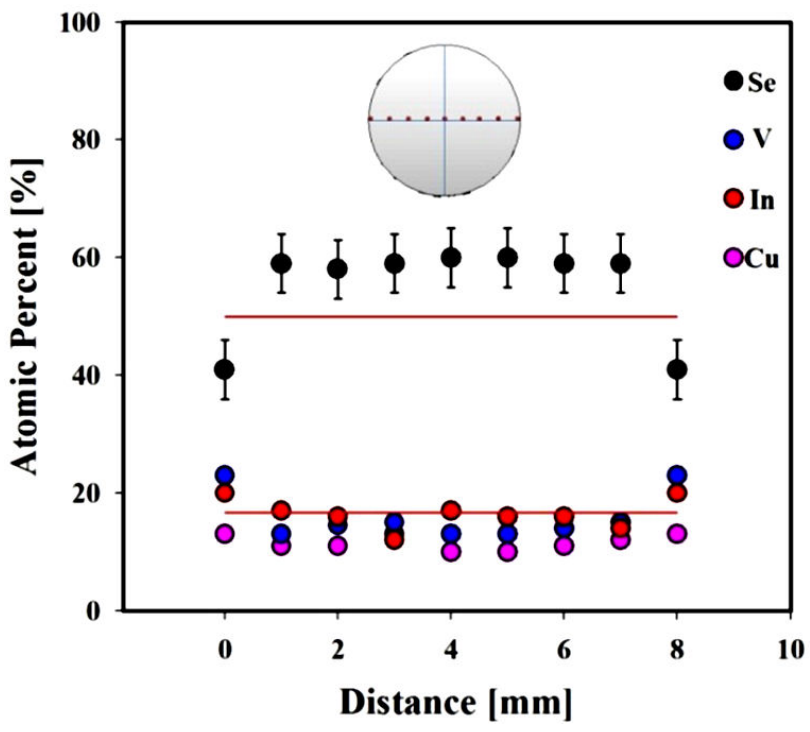

FIGURE 1. SEM measurements for $\mathrm{CuVInSe}_{3}$. The upper image represents the slice and the measured points (in red). The circles are the measured values in atomic percent for each element (the experimental errors are represented only for Se for clarity). The red lines denote the stoichiometric nominal values.

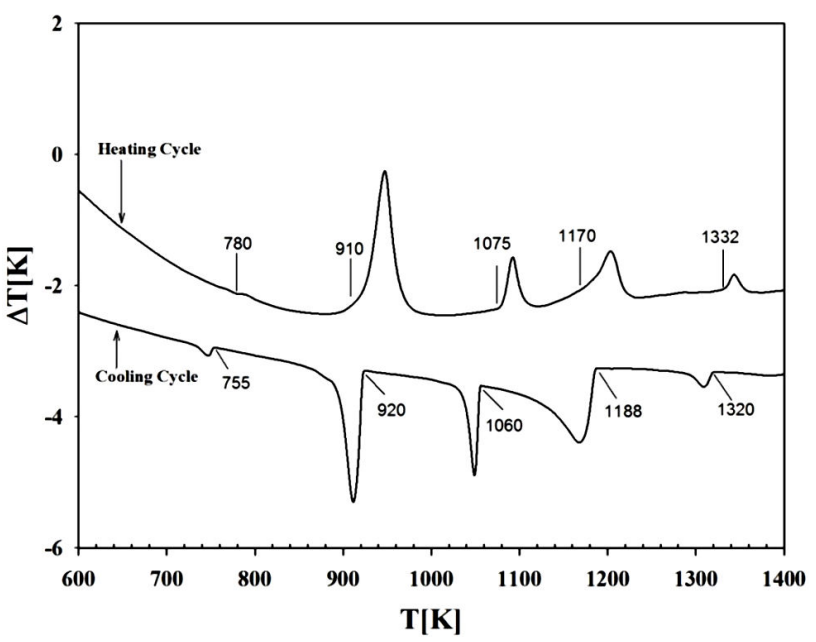

FIgURE 2. DTA thermogram for $\mathrm{CuVInSe}_{3}$. The labels indicate the thermal transitions in the heating and cooling cycles.

out. For Se, the measured values are $\sim 3 \%$ higher that the estimated experimental error $( \pm 5 \%)$; for cations $\mathrm{Cu}$, In and 


\begin{tabular}{cccc}
\hline \hline TABLE II. Results of Rietveld refinement for $\mathrm{CuVInSe}_{3}$ & & \\
\hline Molecular formula & $\mathrm{CuVInSe}_{3}$ & $\mathrm{D}_{\text {calc }}$ & $5.29\left(\mathrm{~g} / \mathrm{cm}^{3}\right)$ \\
Molecular weight & $1243.0(\mathrm{~g} / \mathrm{mol})$ & $\mathrm{N}^{\circ}$ step intensities & 4001 \\
Crystal system & Orthorhombic & $\mathrm{N}^{\circ}$ independent reflections & 153 \\
Space group & $\mathrm{P} \overline{4} 2 \mathrm{c}\left(\mathrm{N}^{\circ} 112\right)$ & Peak-shape profile & Pseudo-Voigt \\
$\mathrm{Z}$ & $2.667(8 / 3)$ & Rexp & $6.6 \%$ \\
$\mathrm{a}$ & $5.7909(4)$ & $\mathrm{Rp}$ & $8.7 \%$ \\
$\mathrm{c}$ & $11.625(1)$ & $\mathrm{Rwp}$ & $8.8 \%$ \\
$\mathrm{~V}$ & $389.84(5)$ & $\mathrm{S}$ & 1.3 \\
\hline
\end{tabular}

$R_{\exp }=100\left[(N-P+C) / \sum_{w}\left(y_{\mathrm{obs}}^{2}\right)\right]^{1 / 2}, \quad N-P+C$ is the number of degrees of freedom.

$R_{p}=100 \sum\left|y_{\text {obs }}-y_{\text {calc }}\right| / \sum\left|y_{\text {obs }}\right| \quad R_{w p}=100\left[\sum_{w} \| y_{\text {obs }}-\left.y_{\text {calc }}\right|^{2}\right]^{1 / 2} \quad S=\left[R_{\mathrm{wp}} / R_{\text {exp }}\right]$

$\mathrm{V}$, the measured values are in agreement with nominal in the range of the experimental error.

\subsection{Differential thermal analysis (DTA)}

DTA runs were carried out on the sample as indicated above. The transition temperatures as well as the type of melting were obtained from the peaks on the DTA heating and cooling curves. Each transition temperature was determined from the base intercept of the tangent to the leading edge of the peak in the differential signal (see Fig. 2). It can be observed that $\mathrm{CuVInSe}_{3}$ show several thermal transitions before melting at $\sim 1332 \mathrm{~K}$. The shape of the peaks suggests that transitions (in the heating cycle) at 780,910 and $1075 \mathrm{~K}$ are of the type solid $\rightarrow$ solid, whereas at $1170 \mathrm{~K}$ is a solid $\rightarrow$ solid + liquid transition.

\subsection{X-ray powder diffraction analysis}

The X-ray powder pattern of $\mathrm{CuVInSe}_{3}$ is shows in Fig. 3. In

this plot it is possible to observe small amounts of a second phase, which was identified as $\mathrm{V}_{3} \mathrm{Se}_{4}$, PDF $\mathrm{N}^{\circ}$ 84-2431 [17]. The peak positions of the main phase $\left(\mathrm{CuVInSe}_{3}\right)$ were indexed using Dicvol04 [18], which gave an unique solution in a tetragonal cell with $a=5.788(2) \AA$ and $c=11.630(2) \AA$. By analyzing the crystallographic characteristics of $\mathrm{CuVInSe} \mathrm{S}_{3}$ with those of other I-II-III-VI ${ }_{3}$ related compounds, it is found that this material is isomorphic with $\mathrm{CuFeInSe}{ }_{3}$ which crystalize with a P-chalcopyrite structure [8]. So, in order to refine the structural parameters of $\mathrm{CuVInSe}_{3}$, the space group $\mathrm{P} \overline{4} 2 \mathrm{c}\left(\mathrm{N}^{\circ} 112\right)$ and the atomic position parameters of $\mathrm{CuFeInSe}{ }_{3}$ were taken as the starting values.

The Rietveld [19] refinement was performed using the Fullprof program [20]. The indexed unit cell results were taken as starting parameters. Atomic positions of $\mathrm{V}_{3} \mathrm{Se}_{4}$ [21] were included as secondary phase in the refinement. The angular dependence of the peak full width at half maximum (FWHM) was described by the Cagliotti's formula [22]. The parameterized Thompson-Cox-Hastings pseudo-Voigt profile function [23] was used for the simulation of the peak shapes. The background of the XRD data was refined with a polynomial with six coefficients. The thermal motion of the atoms was described by one overall isotropic temperature factor. The final figures of merit for 25 instrumental and structural variables were: $R_{\exp }=6.6 \%, R_{p}=8.7 \%, R_{w p}=8.8 \%$, $S=1.3$, for 4501 step intensities and 153 independent reflections. See Table II.

Figure 3 shows the observed, calculated and difference profile for the final cycle of Rietveld refinement. The lower trace is the difference curve between observed and calculated patterns. The Bragg reflections are indicated by vertical bars. Unit cell parameters, atomic coordinates and isotropic temperature factor are shown in Table III.

Table IV shows the distance lengths and bond angles for $\mathrm{CuVInSe}_{3}$. Additional information that can be extracted from this study based on the Rietveld method is a semi-quantitative analysis of the two phases present in the X-ray diffraction pattern [24]. The final refinement converged to $t$ he following weight fraction percentages: $\mathrm{CuVInSe}_{3}(95.3 \%)$ and $\mathrm{V}_{3} \mathrm{Se}_{4}$ $(4.7 \%)$.

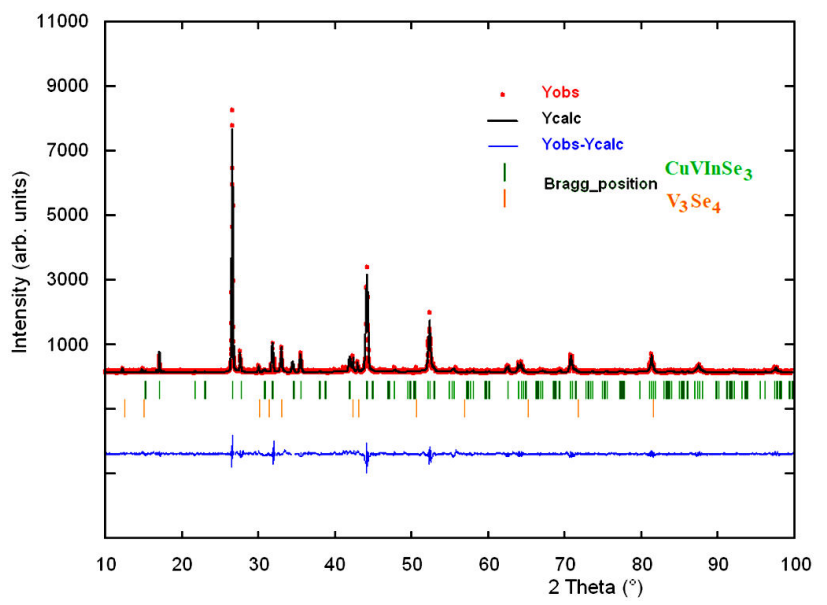

FIGURE 3. Final Rietveld plot showing the observed calculated and difference pattern for the $\mathrm{CuVInSe}_{3}$ compound. The Bragg reflections for both phases are indicated by vertical bars. 
TABLE III. Unit cell, atomic coordinates, isotropic temperature factors for $\mathrm{CuVInSe}_{3}$, derived from the Rietveld refinement $\mathrm{M}=(\mathrm{Cu} 1+\mathrm{V} 1+\operatorname{In} 1)$

\begin{tabular}{|c|c|c|c|c|c|c|c|}
\hline \multicolumn{8}{|c|}{ Space group $\mathrm{P} \overline{4} 2 \mathrm{c},\left(\mathrm{N}^{\circ} 112\right), \mathrm{Z}=2.667(8 / 3), \eta=1.00 a=5.7909(4) \AA, c=11.625(1) \AA, \mathrm{V}=389.84(5) \AA^{3}$} \\
\hline Atom & Ox. & Site & $\mathrm{x}$ & $\mathrm{y}$ & $\mathrm{z}$ & foc & $\mathrm{B}\left(\AA^{2}\right)$ \\
\hline $\mathrm{Cu}$ & +1 & $2 \mathrm{e}$ & 0 & 0 & 0 & 1 & $0.4(4)$ \\
\hline $\mathrm{V}$ & +2 & $2 d$ & 0 & $1 / 2$ & $1 / 4$ & 1 & $0.4(4)$ \\
\hline \multirow[t]{2}{*}{ In } & +3 & $2 b$ & $1 / 2$ & 0 & $1 / 4$ & 1 & $0.4(4)$ \\
\hline & & $2 f$ & $1 / 2$ & $1 / 2$ & 0 & $1 / 3$ & $0.4(4)$ \\
\hline \multirow[t]{2}{*}{ M } & & $2 f$ & $1 / 2$ & $1 / 2$ & 0 & $1 / 3$ & $0.4(4)$ \\
\hline & & $2 f$ & $1 / 2$ & $1 / 2$ & 0 & $1 / 3$ & $0.4(4)$ \\
\hline $\mathrm{Se}$ & -2 & $8 n$ & $0.2553(5)$ & $0.2572(5)$ & $0.1231(3)$ & 1 & $0.4(4)$ \\
\hline
\end{tabular}

\begin{tabular}{|c|c|c|c|c|c|c|c|}
\hline $\mathrm{Cu}-\mathrm{Se}$ & $2.518(3)$ & $\mathrm{V}-\mathrm{Se}$ & $2.540(3)$ & In-Se & $2.530(3)$ & $\mathrm{M}-\mathrm{Se}$ & $2.456(3)$ \\
\hline Seiii-Cu-Seiv & 108.1(1) & & Seiii-Cu-Sev & & & Seiii-Cu-Se & $108.3(1)$ \\
\hline Seiv-Cu-Sev & $108.3(1)$ & & Seiv-Cu-Se & & & $\mathrm{Sev}-\mathrm{Cu}-\mathrm{Se}$ & 108.1(1) \\
\hline Se-V-Sexii & $108.5(1)$ & & Sex-V-Sexi & & & Sex-V-Se & $108.5(1)$ \\
\hline Sex-V-Sexii & $111.4(1)$ & & Sexi-V-Se & & & Sexi-V-Sexii & $108.5(1)$ \\
\hline Se-In-Sei & $107.9(1)$ & & Se-In-Seviii & & & Se-In-Seix & $108.7(1)$ \\
\hline Seviii-In-Sei & $108.7(1)$ & & Seviii-In-Seix & & & Sei-In-Seix & $111.9(1)$ \\
\hline
\end{tabular}

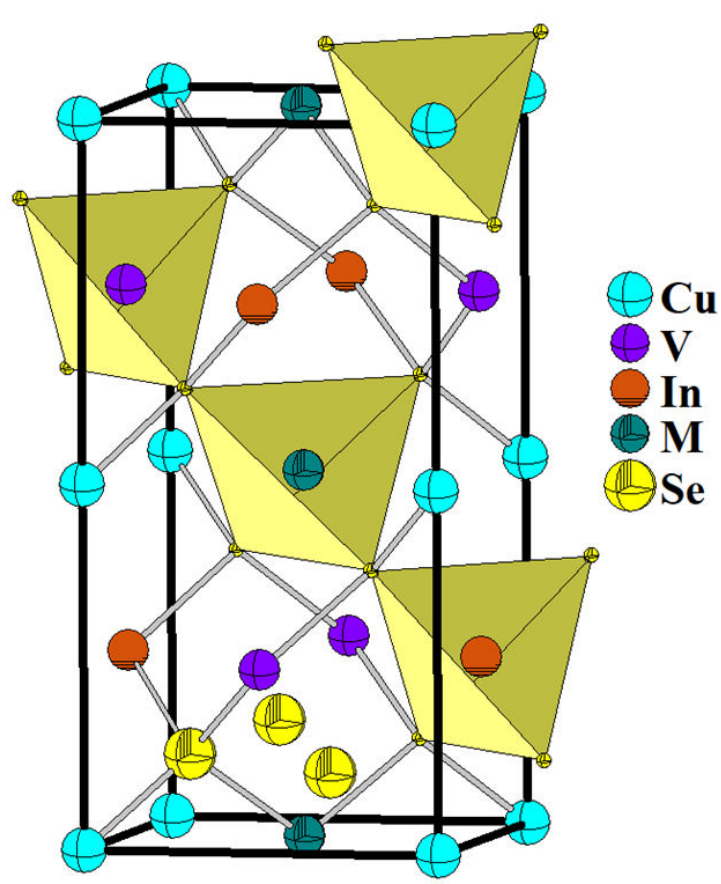

FIGURE 4. Unit cell diagram for the quaternary chalcogenide $\mathrm{CuVInSe}{ }_{3}$, showing the tetrahedra around the cations.

An important structural characteristic is the parameter of tetragonal lattice distortion, which is determined as a deviation of the ratio $\eta=c / 2 a$ ( $a$ and $c$ are unit-cell parameters) from unity [25]. The value of $\eta$ show in Table II, close to unity, is indicative of small lattice distortions in the sample synthesized.

$\mathrm{CuVInSe}_{3}$ crystallize with a $P$-chalcopyrite structure in a normal adamantane-structure compound [1]. In this quaternary compound, the introduction of vanadium (V) into the $\mathrm{CuInSe}_{2}$ chalcopyrite composition produces an effect of dilution leaving the cell volume almost unchanged, with a degradation of symmetry from the chalcopyrite structure $\mathrm{I} \overline{4} 2 \mathrm{~d}$ to the P-chalcopyrite structure $\mathrm{P} \overline{4} 2 \mathrm{c}$. The Se anions form a close-packed arrangement, where each anion is coordinated by four cations located at the corners of a slightly distorted tetrahedron. All cations are similarly coordinated by four anions. Figure 4 shows a polyhedral view of the crystal structure with the four types of atoms-centered tetrahedra $\mathrm{CuSe}_{4}$, $\mathrm{VSe}_{4}, \mathrm{InSe}_{4}$ and $\mathrm{MSe}_{4}$ where all polyhedra are oriented in the same direction and are connected by the corners.

The interatomic distances are shorter than the sum of the respective ionic radii for structures tetrahedrally bonded [26]. The bond distances $\mathrm{Cu}-\mathrm{Se}$ [2.518(3) $\AA$ ], V-Se [2.540(3) $\AA]$ and In-Se [2.530(3) $\AA$ ] agree well with those observed in other adamantane compounds such as CuInSe 2 [27], $\mathrm{CuFe}(\mathrm{Al}, \mathrm{Ga}, \mathrm{In}) \mathrm{Se}_{3} \quad[8,13], \mathrm{CuFe}_{2}(\mathrm{Al}, \mathrm{Ga}, \mathrm{In}) \mathrm{Se}_{4} \quad[12,16]$, $\mathrm{CuNi}(\mathrm{Ga}, \mathrm{In}) \mathrm{Se}_{3}$ [14], and $\mathrm{Cu}_{3} \mathrm{VSe}_{4}$ [28].

\section{Conclusions}

A new quaternary chalcogenide has been synthetized and structurally characterized. The DTA indicates that this com- 
pound melts at $1332 \mathrm{~K}$. The crystals of $\mathrm{CuVInSe} \mathrm{S}_{3}$ belong to the tetragonal system with space group $\mathrm{P} \overline{4} 2 \mathrm{c}$. This material, a new compound of the I-II-III- $\mathrm{VI}_{3}$ family of semiconductors, have an adamantane structure and consists of a threedimensional arrangement of slightly distorted $\mathrm{CuSe}_{4}, \mathrm{VSe}_{4}$ and $\mathrm{InSe}_{4}$ tetrahedra connected by common corners.

\section{Acknowledgments}

This work was supported by CDCHT-ULA and FONACIT (Grants LAB-97000821, PEII-1697 and project $\mathrm{N}^{\circ}$ 2011001341).
1. E. Parthé Wurtzite and Sphalerite Structures. In: J.H. Westbrook, R.L. Fleischer (Eds), Intermetallic Compounds, Principles and Applications. Vol. 1, John Wiley \& Sons, Chichester, UK, Chap. 14 (1995).

2. P. Grima-Gallardo, K. Cárdenas, M. Quintero, J. Ruiz, and G.E. Delgado, Mater. Res. Bull. 36 (2001) 861.

3. P. Grima Gallardo et al., phys. stat. sol. (a), 193 (2002) 217.

4. P. Grima-Gallardo, M. Muñoz, G.E. Delgado, J.M. Briceño, and J. Ruiz, phys. stat. sol. (b), 241 (2001) 1789.

5. P. Grima-Gallardo et al., Mater. Res. Bull. 42 (2007) 2067.

6. P. Grima-Gallardo et al., phys. stat. sol. (a), 204 (2007) 1093.

7. P. Grima-Gallardo et al., J. Alloys Comp. 630 (2015) 146.

8. A.J. Mora, G.E. Delgado, and P. Grima-Gallardo, phys. stat. sol. (a), 204 (2007) 547.

9. W. Höenle, G. Kuehn, and U.C. Boehnke, Cryst. Res. Technol. 23 (1988) 1347.

10. Y. Shapira et al., Phys. Rev. B, 37 (1988) 411.

11. H. Katagiri et al., Thin Solid Films, 517 (2009) 2455.

12. G.E. Delgado, A.J. Mora, P. Grima-Gallardo, and M. Quintero, J. Alloys Comp. 454 (2008) 306.

13. G.E. Delgado et al., Cryst. Res. Technol. 44 (2009) 548.

14. G.E. Delgado et al., Bull. Mater. Sci. 33 (2010) 637.
15. G.E. Delgado, E. Quintero, R. Tovar, P. Grima-Gallardo, and M. Quintero, J. Alloys Comp. 613 (2014) 143.

16. G.E. Delgado et al., Bull. Mater. Sci. 38 (2015) 1061.

17. International Centre for Diffraction Data (ICDD), Powder Diffraction File (Set 1-65). (Newtown Square, PA, USA, 2013).

18. A. Boultif and D. Louër, J. App. Cryst. 37 (2004) 724.

19. H.M. Rietveld, J. App. Cryst. 2 (1969) 65.

20. J. Rodriguez-Carvajal, Phys. B: Cond. Matter, 192 (1993) 55.

21. Kallel and H.J. Boller, J. Less-Common Metals, 102 (1984) 213.

22. G. Cagliotti, A. Paoletti, and F.P. Ricci, Nucl. Instrum. 3 (1958) 223.

23. P. Thompson, D.E. Cox, and J.B. Hastings, J. App. Cryst. 20 (1987) 79 .

24. R.J. Hill and J.C. Howard, J. App. Cryst. 20 (1987) 467.

25. E. Rodulfo de Gil, phys. stat. sol. (a), 70 (1982) 519.

26. S.D. Shannon, Acta Cryst. A. 32 (1976) 751.

27. K.S. Knight, Mater. Res. Bull. 27 (1992) 161.

28. K.O. Klepp, D. Gurtner, and Z. Krystallogr, New Cryst. Struct. 215 (2004) 4. 